\title{
ANÁLISE TECNOLÓGICA NO USO DA ÁGUA DO RIO CARIÚS PARA A AGRICULTURA IRRIGADA DO MUNICÍPIO DE CARIÚS-CE
}

Yure Révelles da Silva Moura ${ }^{1}$ Otácio Pereira Gomes ${ }^{2}$

Fabiano Luiz Alves Barros ${ }^{3}$

Resumo: Esse trabalho concentra-se em identificar o grau de modernização tecnológica dos irrigantes do município de Cariús - Ceará, por meio de um índice de fator tecnológico. O método de análise consistiu no processo da análise fatorial (ACP) e na análise dos custos (fixos e variáveis) das atividades. Para a operacionalização dos dados foi utilizado o software RStudio. Os resultados apontam que estes irrigantes em sua maioria possuem níveis tecnológicos considerados baixos e médios, sem contar que ainda existe a falta de apoio por parte dos órgãos que administram o município. Já com relação à análise dos custos variáveis constatou-se que gastos com fertilizante foi o componente de maior impacto na sua composição de custos, já em relação aos custos fixos, destaca-se a remuneração do empresário como o fator de maior representatividade.

Palavras-chave: Custos. Irrigantes. Índice tecnológico.

\section{TECHNOLOGICAL ANALYSIS IN THE USE OF CARIÚS RIVER WATER FOR IRRIGATED AGRICULTURE OF CARIÚS-CE MUNICIPALITY}

\begin{abstract}
This work focuses on identifying the degree of technological modernization of irrigants in the municipality of Cariús - Ceará, by a technological factor index. The method of analysis consisted of the factorial analysis process (PCA) and the analysis of the costs (fixed and variable) of the activity. For the operation of the data the RStudio software was used. The results indicate that these irrigators in their majority have technological levels considered low and medium, not counting that there is still the lack of support on the part of the organs that administer the municipality. Regarding the analysis of variable costs, it was observed that fertilizer expenditure was the component with the greatest impact in its composition, already in relation to fixed costs, the entrepreneur's remuneration stands out as the most representative factor.
\end{abstract}

Keywords: Costs. Irrigating. Technological index.

\section{ANÁLISIS TECNOLÓGICO EN EL USO DEL AGUA DEL RÍO CARIÚS PARA LA AGRICULTURA IRRIGADA DEL MUNICIPIO DE CARIÚS-CE}

Resumen: Este trabajo se centra en identificar el grado de modernización tecnológica de los irrigantes en el municipio de Cariús - Ceará, mediante un índice de factores tecnológicos. El método de análisis consistió en el proceso del análisis factorial (ACP) y en el análisis de los costos (fijos y variables) de la actividad. Para la operacionalización de los datos se utilizó el software RStudio. Los resultados

\footnotetext{
${ }^{1}$ Universidade Federal do Rio Grande do Norte (UFRN), Departamento de Economia, Natal (RN), Brasil,yure_carius@hotmail.com, https://orcid.org/0000-0001-5100-6646.

${ }^{2}$ Centro Universitário Vale do Salgado (UniVS), Departamento de Ciências Contábeis, Icó (CE), Brasil, otaciopg@gmail.com, https://orcid.org/0000-0003-3532-8412

${ }^{3}$ Universidade Federal de Viçosa (UFV), Departamento de Economia Rural, Viçosa (MG), Brasil, fabianowar@hotmail.com, https://orcid.org/0000-0002-4876-5550
} 
apuntan que estos riegos en su mayoría poseen niveles tecnológicos considerados bajos y medios, sin contar que aún existe la falta de apoyo por parte de los órganos que administran el municipio. En cuanto al análisis de los costos variables se constató que gastos con fertilizante fue el componente de mayor impacto en su composición, ya en relación a los costos fijos, se destaca la remuneración del empresario como el factor de mayor representatividad.

Palabras clave: Costos. Irrigantes. Índice tecnológico.

\section{Introdução}

Em termos globais, o Brasil possui uma boa disponibilidade de água, conta com cerca de $12 \%$ de água doce disposta para o planeta. Esse recurso natural, entretanto, encontra-se distribuído de maneira heterogênea no território nacional. Passam pelo território brasileiro em média cerca de $260.000 \mathrm{~m} 3 / \mathrm{s}$ de água, dos quais $205.000 \mathrm{~m} 3 / \mathrm{s}$ estão localizados na bacia do rio Amazonas, restando para o restante do território $55.000 \mathrm{~m}^{3} / \mathrm{s}$ de vazão média (ANA, 2016).

Além destas questões espaciais, o regime fluvial sofre variações ao longo do ano que estão estreitamente relacionadas ao regime de precipitações. $\mathrm{Na}$ maior parte do Brasil existe uma sazonalidade bem marcada com estações secas e chuvosas bem definidas, de forma que ao final do período seco se pode observar vazões muito abaixo da vazão média e inclusive ausência de água. Essa variabilidade das chuvas e vazões também é interanual, gerada pela ocorrência de anos mais secos e outros mais úmidos. Para manter uma maior garantia de água ao longo do tempo é necessária a utilização de reservatórios ou açudes, capazes de reservar água nos períodos úmidos para ofertar nos períodos mais secos (ANA, 2016).

No Brasil, a agricultura apresenta-se como uma das atividades econômicas de maior destaque, tendo ampla participação no desempenho econômico nacional. $\mathrm{Na}$ região Nordeste a grande maioria das atividades agrícolas possuem um caráter familiar, ocupando em 2006, por exemplo, mais de 6 milhões de pessoas. Entretanto, as questões ambientais e principalmente de cunho climático acabam por limitar o desempenho da atividade na região (CASTRO, 2012).

Os baixos índices de precipitação e a irregularidade no regime pluviométrico na região Nordeste, notadamente no semiárido brasileiro, aliados ao contexto hidro geológico e de elevadas temperaturas, contribuem para os reduzidos valores de disponibilidade hídrica na região. Os elevados índices de evapotranspiração normalmente superam os totais pluviométricos irregulares, configurando taxas negativas no balanço hídrico. A situação dos reservatórios do Nordeste é monitorada 
pela ANA em articulação com os estados e os órgãos responsáveis, com acompanhamento constante dos volumes ocupados de um total de 280 reservatórios, com capacidade igual ou superior a $10 \mathrm{hm}^{3}$, localizados nos nove estados da região (ANA, 2016).

Nesse sentido, Obermaier (2011) faz uma análise sobre as adaptações ocorridas no semiárido brasileiro, que engloba grande parte da região Nordeste. Nesse estudo, o autor volta seus estudos para questões climáticas e de adaptabilidade política, como também populacional. Desse modo, seus estudos mostram a importância de aplicações de métodos eficientes de adaptação com a seca como a irrigação.

Em relação à utilização dos recursos hídricos nas atividades irrigadas Christofidis (2003) afirma que o setor agrícola é o maior consumidor de água e associa essa característica ao fato de que a agricultura é uma forma de produção alimentícia essencial para a vida humana, e a água um bem não durável, consolidando como essencial a busca de uma melhor gestão desses recursos.

No estado do Ceará, a Companhia de Gestão dos Recursos Hídricos (COGERH, 2015), informa a existência de doze Bacias Hidrográficas, com destaque para a Bacia do Alto Jaguaribe, com a segunda maior capacidade de armazenamento do estado.

O Instituto de Estudos e Pesquisas Para o Desenvolvimento do Estado do Ceará (INESP, 2009) cita o Rio Jaguaribe como o principal fluxo hídrico da Bacia Hidrográfica em questão e dá relevante importância aos seus afluentes e suas contribuições para o desenvolvimento socioeconômico da região ${ }^{4}$. Com relação ao Rio Cariús, a COGERH (2015) cita o rio em questão como um dos principais afluentes do Jaguaribe, cortando municípios da Mesorregião Sul e Centro Sul do Ceará e cortando o município de Cariús no sentido Sul - Norte.

Assim o objetivo desse estudo concentra-se em identificar o grau de modernização tecnológica dos irrigantes que utilizam o Rio Cariús por meio de um

\footnotetext{
${ }^{4}$ A produção agrícola atrelada à utilização da água do rio Cariús é de extrema importância para a região como um todo. Pode-se salientar que as principais culturas produzidas no município de Cariús com destaque em relação ao Estado do Ceará são a produção de amendoim com casca (38,796 ton) e fava-grãos (203,949 ton). No tocante á produção municipal interna, observa-se que o milho contribui com $70,9 \%$ e a banana com $21,9 \%$ são as culturas com maior expressão em produtividade no município. Porém, deve-se atentar para outras culturas que vem ganhando destaque, tais como a goiaba, o maracujá e o mamão.
} 
índice de fator tecnológico, além disso, verificou-se a capacidade de pagamento total e unitária de água bruta utilizada nos cultivos ${ }^{5}$ dos produtores.

\section{Revisão de literatura}

\section{Aspectos históricos da irrigação no Brasil}

$\mathrm{Na}$ literatura, nota-se que a irrigação foi uma das primeiras modificações no ambiente realizadas pelo homem primitivo. As primeiras tentativas de irrigação foram rudimentares, mas a importância do manejo da água tornou-se evidente na agricultura moderna. Tribos nômades puderam estabelecer-se em determinadas regiões, irrigando terras férteis e, assim, assegurando produtividade suficiente para a sua subsistência. Nas civilizações antigas, a irrigação era praticada fazendo-se represamentos de água cercados por diques ao longo do curso dos rios. Com o avanço da tecnologia e divulgação das mesmas, a irrigação espalhou-se por várias partes do mundo.

O conhecimento a respeito do processo e da utilização da irrigação no Brasil é bem antigo. No Brasil credita-se aos padres jesuítas, na antiga fazenda Santa Cruz, no estado do Rio de Janeiro, por volta de 1589, a primazia de terem sido os pioneiros na implantação de sistemas de irrigação para fins agrícolas utilizavam técnicas de irrigação, tais como por gravidade (inundação e sulcos de infiltração) principalmente em cultivos de arroz e produtos hortícolas, mas sendo esses em menor escala apenas para subsistência (PIMENTA, BATISTA, 2009, p.18).

De acordo com os documentos do Banco do Nordeste (2001, pág. 45), "no Brasil, a produção por meio de cultivos irrigados é relativamente recente". Sua evolução ocorreu em quatro fases. Na primeira fase sucedida na metade dos anos 1960, a irrigação se desenvolveu por meio de ações isoladas, dirigidas para alvos específicos, em termos setoriais e espaciais, sem a estrutura de políticas ou de programas nacionais.

A segunda fase aconteceu do final dos anos 1960 à metade da década de 1980. Esse período foi marcado pela criação do Grupo de Estudos Integrados de Irrigação e Desenvolvimento Agrícola (GEIDA), cuja característica se destaca na busca da ampliação do conhecimento global sobre os recursos naturais disponíveis

\footnotetext{
${ }^{5} \mathrm{O}$ que chama a atenção é a quantidade de estabelecimentos produtores no estado. O crescimento de tais culturas deve-se em relação a uma parcela significativa de lavouras permanentes $(458,627$ hectares) e de lavouras temporárias (3.693,634 hectares), contudo a produção é significativa de forma regional, mas com baixa participação no estado do Ceará.
} 
e pela implementação de programas nacionais, como o Programa Plurianual de Irrigação (PPI), em 1969, e o Programa de Integração Nacional (PIN), em 1970. Nessa fase, buscam-se a criação de oportunidades para a manifestação da iniciativa privada na esfera da irrigação, como também o estabelecimento de objetivos e metas para um conjunto de iniciativas consolidadas no projeto do I Plano Nacional de Irrigação.

A terceira fase da irrigação no Brasil tem por marco o Programa Nacional de Irrigação (PRONI) e o Programa de Irrigação do Nordeste (PROINE), ambos do ano de 1986. Essa fase denotou a seguinte particularidade:

\footnotetext{
Divisão mais clara de papéis entre o setor público e a iniciativa privada, no desenvolvimento de projetos de irrigação, restringindo-se a ação do governo à execução de obras coletivas de grande expressão (suporte hidráulico, elétrico e macrodrenagem), cabendo à iniciativa privada as demais providências para sua consecução (BANCO DO NORDESTE, 2001, pág. 40).
}

A quarta fase ocorreu em 1995, quando se percebeu, então, que as várias iniciativas tomadas para implementar a irrigação no Brasil no século XX deveriam ser submetidas a uma nova orientação, buscando, assim, um novo direcionamento para a Política Nacional de Irrigação e Drenagem.

O Brasil possui um grande potencial para agricultura propiciado por uma abundância de terras agricultáveis, mas o percentual que utiliza a irrigação ainda é muito baixo. "O Brasil irriga apenas 2.208.690 ha, de uma área plantada de 54.961 .850 ha, isto é apenas $4 \%$ do total de área plantada" (ALFREDO, sem data, $p$. 2) mostrado o grande potencial para o crescimento que a irrigação ainda tem a ser explorada no Brasil.

\footnotetext{
"A irrigação no Brasil depende de fatores climáticos. No semiárido do Nordeste, é uma técnica absolutamente necessária para a realização de uma agricultura racional, pois os níveis de chuva são insuficientes para suprir a demanda hídrica das culturas. Nas regiões Sul, Sudeste e CentroOeste, pode ser considerada como técnica complementar de compensação da irregularidade das chuvas" (PIMENTA, BATISTA, 2009, p.13).
}

As técnicas de irrigação suprem algumas necessidades do meio ambiente principalmente naquelas áreas onde a incidência pluviométrica é baixa, podendo 
elevar a produtividade, fica nítida a grande importância que a irrigação tem para algumas regiões do nordeste brasileiro e no desenvolvimento da agricultura no país.

O Nordeste é uma das maiores regiões brasileiras em termos de extensão territorial e também é conhecida pelos seus problemas socioeconômicos, mas nos últimos anos, expressou melhorias significativas na renda e no trabalho (NETO, 2014). Essa região é frequentemente assolada pelas secas, principalmente, em sua parte semiárida, bem como pela pobreza, sempre foi alvo de políticas de promessas de solução de suas dificuldades, por diversos governos brasileiros (GOMES, 2015).

Inúmeros foram os empreendimentos criados como forma de amenizar os problemas da região nordestina, pois a falta de recursos hídricos era apontada como uma das consequências da fome e da miséria. De acordo com o Banco do Nordeste (2001, pág.47), "as primeiras tentativas de levar o benefício da irrigação ao semiárido ocorreram na década de 40, pelo hoje Departamento Nacional de Obras Contra as Secas (DNOCS), com a construção de grandes açudes e canais de irrigação", cuja responsabilidade é assistir às populações no período da seca.

De acordo com os relatórios do Ministério da Integração Nacional- BRASIL, (1973 apud BANCO DO NORDESTE, 2001, pág. 49), [...] o Plano Integrado para o Combate Preventivo aos Efeitos das Secas no Nordeste registrava: com um potencial de 16,5 bilhões de metros cúbicos nos açudes públicos, a área irrigada no Nordeste, presentemente, é da ordem de 2.500 ha.

O Grupo Executivo de Irrigação para o Desenvolvimento Agrícola (GEIDA) realizou o primeiro e amplo estudo das possibilidades de irrigação no semiárido, determinando a viabilidade técnico-econômica de 73 projetos (62 localizados no Nordeste) e traçou as diretrizes de uma política de irrigação que vieram constituir a primeira fase do Plano Nacional de Irrigação (BANCO DO NORDESTE, 2001).

\section{Abordagens sobre tecnologia de irrigação}

A tecnologia tem se tornado grande aliada ao produtor no meio rural no que concerne ganhos de produtividade e redução nos custos de insumos. "As tecnologias recentes de irrigação exercem papel fundamental para o aumento da produtividade agrícola, sendo um dos principais instrumentos para a modernização da agricultura brasileira" (ALFREDO, sem data, p. 1).

Inúmeros esforços estão sendo somados na busca de tecnologias redutoras de custos e que apresentem uma alta eficiência no processo produtivo resultando no 
melhoramento da qualidade do produto ofertado. Segundo Alfredo (sem data, p. 12) "o aumento de produtividade e a redução de custos somente será possível com o estabelecimento de um padrão de gerenciamento adequado qualificado nas unidades produtivas, bem como na adoção maciça de tecnologia e insumos".

Ao longo dos anos, com a difusão da irrigação por várias partes do mundo, o aperfeiçoamento de novas técnicas tem sido alvo dos novos avanços da tecnologia para o campo. De acordo com Christofidis e Santos (2002, 2010, p. 50-54), "é necessária uma atenção especial no que se refere à modernização tecnológica. Máquinas, equipamentos, tubulações e implementos devem ser adequados às áreas a serem irrigadas e às reais possibilidades financeiras do agricultor. Faz-se mister, ainda, a substituição dos métodos de irrigação de baixa eficiência por equipamentos e tecnologias que permitam melhor manejo e maior controle da utilização dos recursos hídricos".

"Nessa transformação, surgem, com maior vantagem, os equipamentos de maior facilidade de controle, os de manejo adequado dos sistemas de irrigação por superfície, os que elevam a uniformidade de aplicação de água, como os por aspersão, e os de irrigação localizada como gotejamento e micro aspersão" (CHRISTOFIDIS, 2002, p. 52).

Os métodos de otimização e eficiência são indispensáveis no combate ao desperdício de água e elevação da produtividade, assegurando assim uma conscientização do recurso natural com vista na preservação para as gerações futuras.

De acordo com Souza apud Schumpeter (2008), para que a inovação tecnológica transforme o sistema econômico, é necessário que os empreendedores surjam em blocos e não distribuídos de maneira uniforme ao longo do tempo. Além disso, como, o êxito do empreendimento é que induzirá o ingresso de outros empreendedores, difundindo assim a inovação, o que caracterizou a divisão da teoria em três etapas: invenção, inovação e difusão (FREITAS e BACHA, 2004, pág. 26).

No Brasil, a eficiência da irrigação chega a cerca de $60 \%$. Este contexto implica que para cada dez mil litros de água requeridos por hectare de cultivo, há a necessidade de que mais de 16.600 litros sejam aplicados. Daqueles, $97 \%$ retornam para a atmosfera pela evapotranspiração das plantas. (SANTOS 2010, p. 04) 
Portanto, o aumento da eficiência da utilização da água para irrigação tornase, seguramente, fundamental para a redução do volume hídrico retirado das bacias e consequentemente induz ao consumo consciente por parte do sistema agrícola.

\section{Processo de valoração e cobrança pelo uso da água}

A escassez dos recursos hídricos, tanto no seu componente quantitativo quanto qualitativo, é um fenômeno que tem preocupado os governos de vários países e vem dando mostras visíveis de sua ocorrência em várias partes do território nacional. O crescimento econômico desordenado e a ocupação não apropriada do solo, aliado ao uso perdulário dos recursos da água, têm contribuído para tornar a disponibilidade hídrica em certas bacias hidrográficas incompatível com as demandas nas suas múltiplas modalidades de uso. Neste sentido, faz-se preponderantemente necessário à implementação urgente de políticas de manutenção e cobrança pelo uso dos recursos hídricos e uma gestão que trate desse recurso da forma mais adequada e eficiente (FERNANDEZ e GARRIDO, 2000).

No que se refere a gestão de recursos hídricos, existem dois instrumentos econômicos mais recorrentes em âmbito mundial: a criação de mercados de água no qual são atribuídos direitos privados de água aos agentes econômicos, que os transacionam livremente no mercado - e a cobrança pelo uso da água (MARTINS, 2014).

A cobrança pelo uso da água é um instrumento de gestão fundamental para o equilíbrio entre a oferta e a demanda desses recursos na bacia ou região hidrográfica ${ }^{6}$.

\footnotetext{
"No Brasil, foi adotado o modelo de cobrança pelo uso dos recursos hídricos, cobrança essa que foi definida pela atribuição de um valor monetário ao recurso, na forma de taxas, impostos ou preços cobrados sobre o uso ou contaminação produzidas por suas atividades econômicas, de forma a igualar (ou, ao menos, aproximar) os custos privados e os custos sociais. " (CAMPREGHER, MARTINS, 2014, p.6).
}

\footnotetext{
${ }^{6}$ Além da cobrança pelo uso dos recursos hídricos, os principais instrumentos de gestão desse setor são: (i) planos (diretores) de recursos hídricos; (ii) outorga de direito de uso dos recursos hídricos; (iii) sistemas de informações sobre recursos hídricos; (iv) enquadramento dos mananciais em classes de uso; e (v) compensação aos municípios.
} 
A transformação de valor em preço, que apenas se materializa através da implementação do instrumento de cobrança pelo uso da água, deve levar em consideração vários fatores e circunstâncias. De um lado, a cobrança deve considerar a quantidade de água efetivamente utilizada, seja ela captada (ou derivada) para consumo ou necessária para diluir uma determinada carga de poluente. Porém, a cobrança deve levar em consideração também a condição econômica do usuário, detectada através da sua capacidade de pagamento. Do outro lado, a cobrança pelo uso da água deve considerar a finalidade a que se destinam os recursos da água, a disponibilidade hídrica e a classe de enquadramento de uso do corpo receptor local, bem como o programa de investimentos necessários à boa operacionalidade de uso da bacia, através do grau de regularização ou da vazão de diluição de poluentes assegurado por obras hidráulicas ou ações específicas (FERNANDEZ e GARRIDO, 2000).

Quando se volta o olhar para a região nordeste percebe-se que fatores como: a escassez frequente de água e o consumo hídrico desordenado, tem levado a uma série de questionamentos em relação ao consumo eficiente do recurso hídrico na região, principalmente por parte da agricultura irrigada. Neste sentido, políticas públicas que visem o consumo adequado do recurso, seja ela com a finalidade de produção de bens e serviços ou para atender a demanda da população, se fazem de extrema importância para a preservação e manutenção do mesmo, visto que o recurso natural e finito sendo essa a maior preocupação por parte de pesquisadores e ambientalistas.

Segundo Ferraz (2001, p.3), "o Brasil é titular do desperdício universal da água tratada e encanada, atingindo um percentual de 40\%". Neste contexto fica claro a preocupação com o recurso natural e a sua extração cada vez mais desordenada.

O sistema de irrigação ao ser manuseado da forma incorreta pode ser caracterizado como um instrumento de desperdício, muitas vezes tendo como responsáveis a inexperiência do produtor ao adquirir um sistema com baixo índice tecnológico ou a falta de informação quanto ao manejo adequado.

"Na irrigação, existe muita perda de água devido, principalmente, à baixa eficiência dos sistemas e falta de um monitoramento da quantidade de água necessária e aplicada. Todavia, estas causas não justificam as perdas, visto que estas podem ser minimizadas pelo uso de um sistema de irrigação mais eficiente e de técnicas de manejo adequadas. Com isso, pode-se dizer que a principal causa dos desperdícios de água na agricultura é que o seu uso 
não é cobrado. Com a introdução da cobrança pelo uso da água é de se esperar um uso mais racional, com consequente redução no consumo" (PIMENTA e BATISTA, 2009, p.23).

Como reforça Pimenta e Batista (2009, p. 24) "A cobrança pelo uso da água deverá estimular 0 agricultor irrigante a adotar medidas para evitar perdas e desperdícios e, também, constituir receitas que possam viabilizar financiamentos para a aplicação em projetos e obras hidráulicas e de saneamento".

\section{Metodologia}

\section{Área de estudo}

A pesquisa foi realizada com o grupo de irrigantes do município de Cariús-Ce que utilizam o Rio Cariús como fonte produtora. De acordo com o Instituto de Pesquisa e Estratégia Econômica do Ceará (IPECE, 2012), o município de Cariús está localizado na Mesorregião Centro Sul do Ceará, tendo como municípios limítrofes Iguatu e Jucás ao Norte, Farias Brito e Várzea Alegre ao Sul, Várzea Alegre, Cedro e Iguatu ao Leste e Jucás, Tarrafas e Farias Brito ao Oeste.

A fonte hídrica abordada na pesquisa está localizada na Bacia Hidrográfica do Alto Jaguaribe, passando pelos municípios de Santana do Cariri, Nova Olinda, Crato, Farias Brito e cortando todo o município de Cariús até desaguar no Jaguaribe, como é mostrado na Figura 01.

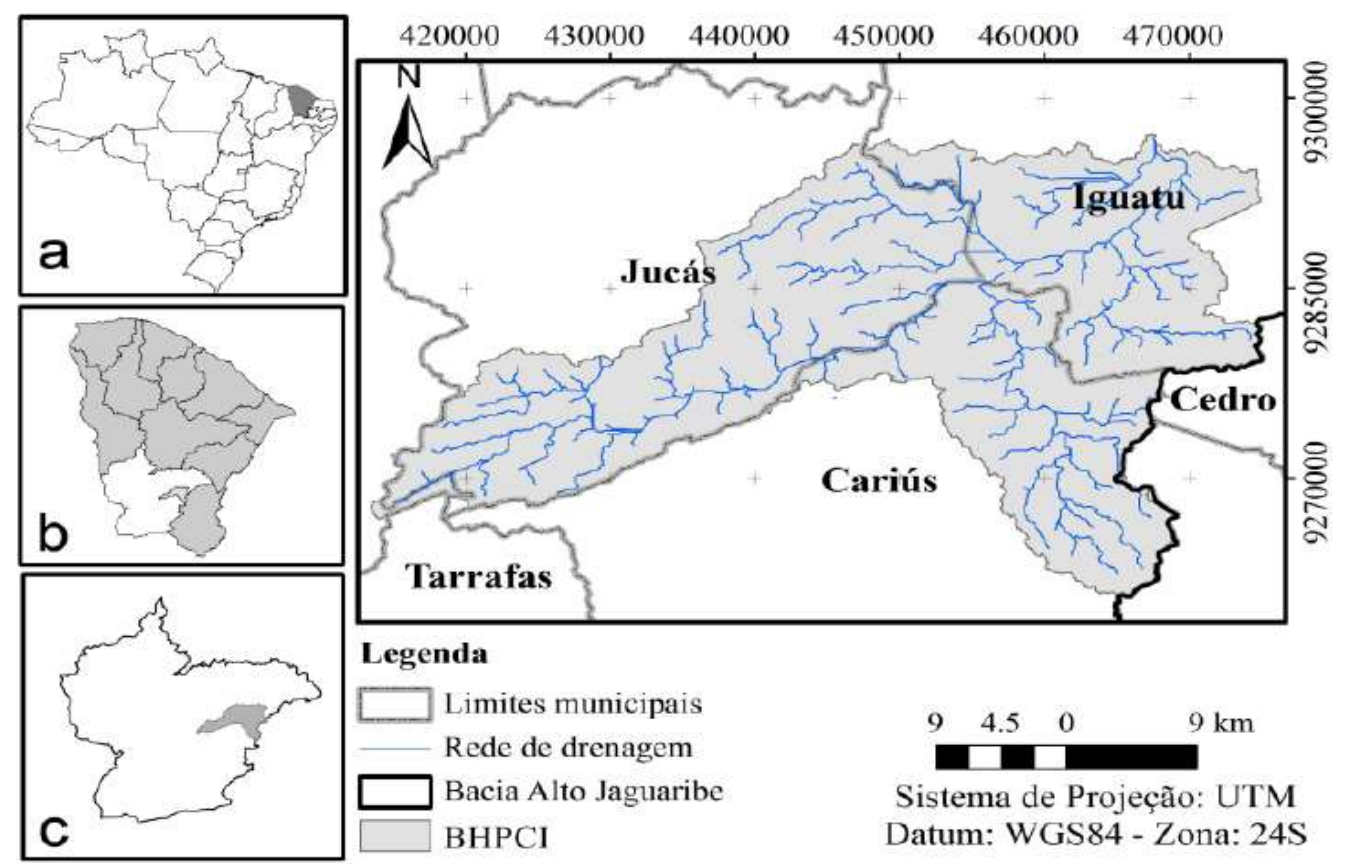

Figura 01 - Localização da bacia hidrográfica Patos, Cariús e Iguatu. 
Fonte: LANDIN (2014).

Notas: 'a', o Estado do Ceará; 'b', sub-bacia do Alto Jaguaribe; e 'c', a localização da Bacia Hidrográfica Patos/Cariús/Iguatu, inserida na sub-bacia do Alto Jaguaribe.

\section{Natureza e fonte dos Dados}

Os dados de natureza primária foram coletados pela técnica de pesquisa de campo do tipo qualitativa e quantitativa descritiva, com o objetivo de conferir hipóteses, delineamento de um problema, análise de um fato e isolamento de variáveis principais (MARCONI; LAKATOS, 1996 apud SOUZA, 2014). Conforme a definição da área de estudo, os dados amostrais foram coletados junto aos irrigantes do município de Cariús-Ce.

A forma de entrevista foi semiestruturada, baseada na aplicação de questionários, que segundo Mattar (1996), tenta por meio da tabulação e cruzamento de informações [...]. No presente estudo, trabalhou-se com dados primários quantitativos e qualitativos. Os dados de natureza secundária foram utilizados de artigos, livros e periódicos que servirão como pontos de referências no estudo em análise. O levantamento dos dados para o estudo refere-se ao ano de 2017.

\section{População e amostra}

A pesquisa foi realizada por amostragem não probabilística por conveniência, levando em conta os irrigantes que exploram a atividade no município de Cariús no Estado do Ceará.

Nos métodos de amostragem não probabilística, as amostras são obtidas de forma não aleatória, ou seja, a probabilidade de cada elemento da população fazer parte da amostra não é igual e, portanto, as amostras selecionadas não se exibem igualmente prováveis (FÁVERO et al., 2009).

O método por conveniência pode ser aplicado quando a participação é voluntária ou os elementos da amostra são escolhidos conveniência ou simplicidade. Logo, foram entrevistados 40 irrigantes.

\section{Métodos de análise}

A metodologia de análise segue dentre outros estudos, a do estudo de Souza (2014). 


\section{Análise Fatorial}

Para estudar o processo de identificação do nível tecnológico implantado pelos irrigantes do município de Cariús, foi utilizada a análise fatorial. Esta técnica tem sido adotada como instrumento de análise em vários estudos, tais como Madeira (2013), Souza (2014) e Gomes (2015), de forma a medir a modernização na agricultura em alguns estados brasileiros, analisar a influência da tecnologia na capacidade de pagamento dos produtores do Perímetro Irrigado Platôs de Guadalupe no Estado do Piauí e analisar a eficiência tecnológica dos fruticultores da região do Cariri, Ceará, respectivamente.

Para aplicação da análise fatorial, foram selecionadas variáveis "indicadoras do nível tecnológico". Neste sentido, a seleção das variáveis adequadas ao fenômeno que se deseja estudar é de extrema importância, pois uma vez a variável incluída na pesquisa tem implicações definitivas nos resultados da análise.

Para a verificação dos pressupostos foi utilizada a normalidade da distribuição dos dados de cada variável utilizando o Teorema do Limite Central, que caso haja um grande número de variáveis aleatórias independentes e identicamente distribuídas, então a distribuição tenderá para uma distribuição normal, à medida que o número dessas variáveis aumente indefinidamente, além da estimação da matriz de correlação para checar a existência de relação entre as variáveis realizada por meio de testes de hipóteses específicos (GUJARATI, 2000).

Para verificar a adequabilidade dos dados para a análise fatorial, foi utilizado o índice Kaiser-Mayer-Olkin (KMO), o teste de esfericidade de Bartlett (BTS) e a Matriz Anti-Imagem.

O procedimento utilizado na pesquisa considerou a extração dos fatores iniciais através da Análise dos Componentes Principais (ACP) que mostra uma combinação linear das variáveis observadas, de maneira a maximizar a variância total explicada. A Análise dos Componentes Principais (ACP) leva em conta a variância total dos dados e, na análise fatorial, os fatores são estimados apenas pela variância comum. A ACP se aplica quando o objetivo da análise for reduzir o número de variáveis para a obtenção de um número menor de fatores necessários para explicar o máximo possível à variância representada pelas variáveis originais.

A escolha do número de fatores se deu por meio do critério da raiz latente (critério de Kaiser) em que se escolhe o número de fatores a reter, em função dos valores próprios acima de 1 (eigenvalues) que mostraram a variância explicada por 
cada fator ou quanto cada fator conseguiu explicar da variância total (MINGOTI, 2005).

Com a finalidade de minimizar a dificuldade de interpretação dos fatores, se utilizou o método de rotação ortogonal (mantendo-se a independência entre eles) varimax, que minimiza o número de variáveis com altas cargas em diferentes fatores permitindo a associação de uma variável a um único fator, mantendo a ortogonalidade entre eles. Como critério para a saída dos escores fatoriais, será utilizado o método da regressão.

A análise fatorial foi realizada com base em indicadores de adoção de tecnologia por produtor, quantidade essa que leva em conta os conceitos estatísticos que afirma: a cada 5 observações, trabalha-se com uma variável (FÁVERO et al. 2009).

\section{Índice Tecnológico dos Irrigantes de Cariús- ITIC}

A análise fatorial permitiu criar um índice tecnológico dos irrigantes de Cariús, com base nas variáveis que mais contribuirão para o nível de tecnologia dos produtores. O Índice Tecnológico dos Irrigantes foi obtido da seguinte forma:

$$
\operatorname{ITIC}_{i}=\sum_{j=1}^{p}\left[\frac{\lambda_{j}}{\sum \lambda_{j}}\right] F_{i j} *
$$

, para todo $\lambda_{j} \geq 1$.

\section{Em que:}

$I T I C i$ = Índice Tecnológico do i-ésimo irrigante de Cariús;

$j$ = é a j-ésima raiz característica;

$p=$ é o número de fatores extraídos na análise;

$F_{i j}^{*}=$ é o j-ésimo escore fatorial do i-ésimo irrigante;

$\sum \lambda j=$ é o somatório das raízes características referentes aos $p$ fatores extraídos.

Para tornar todos os valores dos escores fatoriais $F_{i j}^{*}$ superiores ou iguais a zero, todos eles foram colocados no primeiro quadrante (LEMOS, 2001), antes da construção do ITIC $i$, se utilizou expressão algébrica:

$$
F_{j i}^{*}=\frac{F_{j i}-F_{j}^{\min }}{F_{j}^{\max }-F_{j}^{\min }}
$$




\section{Em que:}

$F_{j}^{\min }$ é o menor escore observado para o j-ésimo fator, e $F_{j}^{\max }$ é o maior escore observado para o j-ésimo fator.

Com os índices parciais calculados, foi realizada a padronização dos mesmos de modo a enquadrá-los no intervalo de zero a um.

Para a operacionalização dos dados foi utilizado o software Rstudio.

\section{Resultados e discussões}

\section{Identificação dos fatores tecnológicos representativos dos irrigantes do município de Cariús, Ceará}

Inicialmente, com o intuito de verificar a coesão dos dados coletados, foi calculado o índice Kaiser-Mayer-Olkin (KMO). Assim, observou-se pela Tabela 01, considerando-se distribuição normal dos dados, que o KMO apresentou valor de 0,680, portanto, indicando que os dados são consistentes, ou seja, é um índice razoável e aceito para análise fatorial. $O$ teste de esfericidade de Bartlett apresentou valor de 79,163, sendo considerado um valor elevado para garantir que a matriz de correlações não é uma matriz identidade, ao nível de significância $0,000 \%$, menor que $0,05 \%$, rejeitando a hipótese nula $\left(\mathrm{H}_{0}\right)$, de que a matriz de correlação é uma matriz identidade. Conclui-se, portanto, que os dados amostrais são adequados para uso da análise fatorial.

Tabela 01 - Teste de KMO (Kaiser Mayer Olkin) e BTS (Teste de Esfericidade de Bartlett)

\begin{tabular}{cc}
\hline KMO & 0,680 \\
Teste de Esfericidade de Bartlett & 79,163 \\
Sig & 0,000 \\
\hline
\end{tabular}

Fonte: Resultados da Pesquisa (2017)

Com o uso da análise fatorial, pelo método dos componentes principais, foram obtidos três fatores característicos, com índices maiores que um, considerando o critério da raiz latente, conforme observado na Tabela 02. Diante disso, determinamse quantos fatores foram utilizados na pesquisa.

Objetivando caracterizar ou representar um total de variáveis originais em um número menor possível de variáveis, a fim de explicar a tecnologia adotada no perímetro irrigado analisado, gerou-se três fatores, considerando-se que o Fator 1 
possui raiz 2,931, o Fator 2 tem raiz 1,595, e para o Fator 3, apresenta uma raiz característica de 1,219, ou seja, todos os fatores atendem a exigência da metodologia de apresentar raízes latentes maiores que 1 , e que em conjunto explicam $63,82 \%$ da variância total dos 9 indicadores de adoção de tecnologia pelos irrigantes do município de Cariús.

Tabela 02 - Valores das raízes características e percentual de variância total explicada pela análise fatorial.

\begin{tabular}{cccc}
\hline Fator & Raiz característica & $\begin{array}{c}\text { Variância explicada pelo fator } \\
(\%)\end{array}$ & $\begin{array}{c}\text { Variância acumulada } \\
(\%)\end{array}$ \\
\hline $\mathbf{1}$ & 2,931 & 28,19 & 28,19 \\
$\mathbf{2}$ & 1,595 & 20,62 & 48,81 \\
$\mathbf{3}$ & 1,219 & 15,01 & $\mathbf{6 3 , 8 2}$ \\
\hline
\end{tabular}

Fonte: Resultados da Pesquisa (2017)

Conforme a Tabela 03 observou-se as cargas fatoriais ou coeficientes de correlação após a rotação dos fatores das 9 variáveis de adoção de tecnologia dos irrigantes e suas respectivas comunalidades, onde o valor das comunalidades é obtido pelo somatório do quadrado das cargas fatoriais de cada variável. Admite-se que valores acima de 0,5 (em negrito) indicam forte associação entre a variável e o fator.

Tabela 03 - Cargas fatoriais rotacionadas das variáveis de tecnologia obtidas na análise fatorial

\begin{tabular}{c|c|c|c|c}
\hline Variáveis & F1 & F2 & F3 & Comunalidades \\
\hline X1- Assistência técnica & $\mathbf{0 , 5 8 8}$ & $-0,488$ & 0,136 & 0,602 \\
X2- Mudas melhoradas & $\mathbf{0 , 7 7 4}$ & 0,085 & 0,187 & 0,642 \\
X3- Escolaridade & 0,282 & $\mathbf{0 , 7 5 1}$ & 0,272 & 0,717 \\
X4- Experiência & $-0,313$ & 0,144 & $\mathbf{0 , 6 7 2}$ & 0,571 \\
X5- Monitoramento de praga & 0,406 & $-0,162$ & 0,733 & 0,729 \\
X6- Adubação & $-0,202$ & $\mathbf{0 , 8 3 6}$ & $-0,221$ & 0,788 \\
X7- Projetos & $\mathbf{0 , 7 4 7}$ & $-0,073$ & $-0,228$ & 0,616 \\
X8- Investimentos & $-0,465$ & $\mathbf{0 , 5 3 7}$ & 0,364 & 0,638 \\
X9- Anotação de decisão & $\mathbf{0 , 6 5 9}$ & $-0,086$ & $-0,022$ & 0,442 \\
\hline
\end{tabular}

Fonte: Resultados da Pesquisa (2017)

O primeiro fator $(\mathrm{F} 1)$, está composto pelas variáveis por: X1 (Assistência técnica), X2 (Mudas Melhoradas), X7 (Fez Projetos) antes de executar o plantio e X9 (Anotações para decisão). 
Em relação às cargas do fator (F2), constatou-se que este possui uma correlação com as variáveis X3 (Escolaridade), X6 (adubação) e X8 (Investimentos). Já analisando o fator (F3) percebeu-se que o mesmo está fortemente ligado apenas à variável X4 (Experiência).

\section{Agrupamentos dos Produtores pelo Índice Tecnológico do Irrigante de Cariús (ITIC)}

Vários são projetos agrícolas que têm como objetivo prioritário oferecer aos produtores melhores oportunidades de produção agrícola, bem como alavancar a economia do município onde produzem.

Por meio da análise fatorial, após a obtenção dos escores fatoriais extraídos pelo método de rotação Varimax, procedeu-se a construção do Índice Tecnológico do Irrigantes do Município de Cariús para os 40 irrigantes pesquisados no período analisado. Em seguida, foi feita a padronização do índice de forma que o mesmo pudesse variar entre zero e um. Quanto mais próximo de um, melhores são os níveis tecnológicos desenvolvidos pelo produtor.

De acordo com a Tabela 04, percebe-se que foram obtidas cinco classes para classificação de Índices Tecnológicos do Irrigantes do Município de Cariús (ITIC), no entanto, vale ressaltar que a análise mostrou somente quatro agrupamentos, porém, consideraram-se os outros para mostrar de maneira concreta, a apresentação dos dados.

O grupo 5 foi caracterizado como muito alto, grupo 4, alto, o grupo 3, médio, o grupo 2 foi classificado com baixo e o grupo 1 como muito baixo. Esta escolha de cinco grupos tomou como base o trabalho de Cunha et al. (2008) que desenvolveu estudos semelhantes sobre classificação e agrupamentos de índices, mediante uma melhor estruturação das variáveis e quantidade das mesmas.

Para os índices classificados como muito baixo, entre 0 e 0,20 , haviam seis irrigantes o que equivale a um percentual de $15 \%$, entre 0,21 e 0,35 (baixo), observa-se a quantidade de onze irrigantes com uma frequência relativa de $27,5 \%$; dezessete irrigantes apresentam índice considerado médio, entre 0,37 e 0,54, com uma frequência relativa de $42,5 \%$, e seis produtores apresentaram índices considerados alto, entre 0,62 e 0,78 , com frequência relativa de $15, \%$. Para os índices entre 0,79 e 1,00 não foram encontrados irrigantes, já que esses seriam 
considerados índices muito altos para adoção de tecnologia, conforme Madeira (2009), Souza (2014) e Gomes (2015).

Tabela 04 - Índice tecnológico, número de irrigantes, segundo os grupos do Índice de adoção de Tecnologia dos Irrigantes do município de Cariús, Ceará, 2017.

\begin{tabular}{cccc}
\hline GRUPOS & ITIC & Número de produtores & Frequência relativa \\
\hline 1- Muito Baixo & $0-0,20$ & 6 & $15 \%$ \\
2- Baixo & $0,21-0,35$ & 11 & $27,5 \%$ \\
3- Médio & $0,37-0,54$ & 17 & $42,5 \%$ \\
4- Alto & $0,55-0,78$ & 6 & $15 \%$ \\
5-Muito Alto & $0,79-1,00$ & 0 & $0 \%$ \\
Informações válidas & - & $\mathbf{4 0}$ & $\mathbf{1 0 0 , 0 0}$ \\
\hline
\end{tabular}

Fonte: Resultados da Pesquisa (2017)

As variáveis que mais contribuíram para indicar melhorias de adoção do nível tecnológico do referido índice foram: X1 (Assistência técnica), X2 (Mudas Melhoradas), X7 (Fez Projetos) antes de executar o plantio e X9 (Anotações para decisão), resultado justificado pela maior variância apresentada pelos dados, num total de $28,19 \%$, representadas pelo fator 1 (Tabela 02).

$\mathrm{Na}$ Tabela 05, que representa a análise por grupos de produtores em relação às variáveis representativas do fator 1, percebe-se que, quanto à variável Assistência técnica, que considerou o índice de adoção de tecnologia, para o grupo 1 (muito baixo), do total de irrigantes do grupo, cinco irrigantes afirmaram que receberem algum tipo de assistência técnica correspondendo por 83,3\%. A análise do grupo 2 (índice baixo) mostrou que sete (67,6\%), afirmaram receber assistência técnica. Para o grupo 3 (índice médio), observa-se que, nove irrigantes $(52,9 \%)$ afirmaram receber assistência técnica e oito $(47,1 \%)$ disseram não receber assistência técnica. A análise do grupo 4 (índice alto), observa-se que quatro $(66,7 \%)$ não recebem nenhum tipo de assistência técnica e dois (33,3\%) afirmaram receber algum tipo de assistência. Tal fato se confirma pela falta de apoio por parte dos órgãos que administram o município e a falta de técnicos para acompanha-los, contudo, seria muito importante a utilização dessa ferramenta para o aumento da produtividade da lavoura.

Para a variável mudas melhoradas, observa-se que o grupo 1 (índice muito baixo), todos fazem o uso de mudas melhoradas. O grupo 2 (índice baixo) 10 irrigantes (90,9\%) afirmaram utilizar mudas melhoradas, o grupo 3 (índice médio) doze irrigantes $(70,6 \%)$ não utilizam algum tipo de muda melhorada. $O$ grupo 4 (índice alto) seis irrigantes (100\%) não fazem o uso de mudas melhoradas. 
Quanto a variável cobertura morta, pode-se observar que o grupo 1 (índice muito baixo), cinco irrigantes $(83,3 \%)$ utilizam a cobertura morta em sua lavoura e apenas um afirmou não utilizar. O grupo 2 (índice baixo) dez (90,9\%) responderam fazerem o uso de cobertura morta. $\mathrm{O}$ grupo 3 (índice médio) observamos que quinze irrigantes $(88,2 \%)$ fazem cobertura morta e dois $(11,8 \%)$ não realizam. $O$ grupo 4 (índice alto) mostra que cinco $(83,3 \%)$ irrigantes utilizam a cobertura morta e apenas 1 não utiliza. Contudo, pôde-se observar a preocupação dos irrigantes na proteção do solo e de sua cultura para melhor aproveitamento dos nutrientes.

Com relação a variável fez projeto, o grupo 1 (índice muito baixo) seis irrigantes (100\%) afirmaram fazer algum tipo de projeto para iniciarem suas culturas. O grupo 2 (índice baixo) seis (54,5\%) afirmaram fazer projeto e cinco $(45,5 \%)$ não realizam nenhum protejo. O grupo 3 (índice médio) sete irrigantes $(41,2 \%)$ responderam que fazem projeto e dez $(58,8 \%)$ não realizam nenhum projeto. $O$ grupo 4 (índice alto) apenas 1 (16,7\%) afirmou fazer algum tipo de projeto e cinco $(83,3 \%)$ não realizam nenhum tipo de projeto. Diante disso, percebe-se a importância que a realização de projetos tem para o produtor e para o sucesso de sua atividade agrícola.

Tabela 05 - Frequência absoluta e relativa das variáveis do fator 1 que mais contribuíram para o índice dos irrigantes do munícipio de Cariús, Ceará.

\begin{tabular}{|c|c|c|c|c|c|}
\hline \multirow[b]{2}{*}{ VARIÁVEIS } & \multicolumn{5}{|c|}{ ÍNDICE } \\
\hline & & $\begin{array}{c}\text { Grupo } 1 \\
\text { MUITO BAIXO }\end{array}$ & $\begin{array}{c}\text { Grupo } 2 \\
\text { BAIXO }\end{array}$ & $\begin{array}{l}\text { Grupo } 3 \\
\text { MÉDIO }\end{array}$ & $\begin{array}{c}\text { Grupo } 4 \\
\text { ALTO }\end{array}$ \\
\hline \multirow{4}{*}{$\begin{array}{l}\text { ASSINSTÊNCIA } \\
\text { TÉCNICA }\end{array}$} & SIM & $\begin{array}{c}5 \\
83,3 \%\end{array}$ & $\begin{array}{c}7 \\
63,6 \%\end{array}$ & $\begin{array}{c}9 \\
52,9 \%\end{array}$ & $\begin{array}{c}2 \\
33,3 \%\end{array}$ \\
\hline & NÃO & 1 & 4 & 8 & 4 \\
\hline & NAU & $16,7 \%$ & $36,4 \%$ & $47,1 \%$ & $66,7 \%$ \\
\hline & TOTAL & $\begin{array}{c}6 \\
100,0 \%\end{array}$ & $\begin{array}{c}11 \\
100,0 \%\end{array}$ & $\begin{array}{c}17 \\
100,0 \%\end{array}$ & $\begin{array}{c}6 \\
100,0 \%\end{array}$ \\
\hline \multirow{5}{*}{$\begin{array}{c}\text { MUDAS } \\
\text { MELHORADAS }\end{array}$} & & 6 & 10 & 5 & 0 \\
\hline & SIM & $100,0 \%$ & $90,9 \%$ & $29,4 \%$ & $0,0 \%$ \\
\hline & Nã & 0 & 1 & 12 & 6 \\
\hline & NAO & $0,0 \%$ & $9,1 \%$ & $70,6 \%$ & $100,0 \%$ \\
\hline & TOTAL & $\begin{array}{c}6 \\
100,0 \%\end{array}$ & $\begin{array}{c}11 \\
100.0 \%\end{array}$ & $\begin{array}{c}17 \\
100.0 \%\end{array}$ & $\begin{array}{c}6 \\
100.0 \%\end{array}$ \\
\hline \multirow{5}{*}{$\begin{array}{c}\text { COBERTURA } \\
\text { MORTA }\end{array}$} & & 5 & 10 & 15 & 5 \\
\hline & SIM & $83,3 \%$ & $90,9 \%$ & $88,2 \%$ & $83,3 \%$ \\
\hline & Nã & 1 & 1 & 2 & 1 \\
\hline & NAU & $16,7 \%$ & $9,1 \%$ & $11,8 \%$ & $16,7 \%$ \\
\hline & TOTAL & $\begin{array}{c}6 \\
100,0 \%\end{array}$ & $\begin{array}{c}11 \\
100,0 \%\end{array}$ & $\begin{array}{c}17 \\
100,0 \%\end{array}$ & $\begin{array}{c}6 \\
100,0 \%\end{array}$ \\
\hline \multirow{4}{*}{ FEZ PROJETO } & & 6 & 6 & 7 & 1 \\
\hline & SIM & $100,0 \%$ & $54,5 \%$ & $41,2 \%$ & $16,7 \%$ \\
\hline & NÃO & 0 & 5 & 10 & 5 \\
\hline & & $0,0 \%$ & $45,5 \%$ & $58,8 \%$ & $83,3 \%$ \\
\hline
\end{tabular}




\begin{tabular}{lccccc}
\hline TOtAL & 6 & 11 & 17 & 6 \\
& & $100,0 \%$ & $100,0 \%$ & $100,0 \%$ & $100,0 \%$ \\
\hline
\end{tabular}

Fonte: Elaborada com base nos resultados da pesquisa (2017)

A Tabela 06 mostra a análise, por grupo, de irrigantes em relação às variáveis representativas do fator 2. Quanto à variável Escolaridade, vale destacar que, para o grupo 1 (índice muito baixo), apenas um irrigante (16,7\%) é considerado analfabeto (AN) e $5(83,3 \%)$ possuem o ensino fundamental incompleto. Para os irrigantes do grupo 2(índice baixo), percebe-se, também, que 2 deles (18,2\%\%) são analfabetos (AN), oito irrigantes $(72,7 \%)$ tem o ensino fundamental incompleto e apenas $1(9,1 \%)$ possui o ensino médio incompleto. Em seguida, aparece o grupo 3 (índice médio), com relação à variável escolaridade, onde dois (11,8\%) são analfabetos (AN), dez irrigantes (58,8\%) possuem Ensino Fundamental Incompleto (EFI), e três $(17,6 \%)$ apresentam Ensino Superior (EMC). O grupo 4 (índice alto) considerado como o melhor quanto no quesito escolaridade apresentando, apenas dois irrigantes $(33,3 \%)$ afirmaram possuir o Ensino Médio Incompleto (EMI), três (50\%) tem o Ensino Superior (ES) e 1 (16,7\%) possuía o técnico ,ou seja, observa-se que, quando se trata do quesito escolaridade, ainda prevalece um baixo nível entre os irrigantes, reflexo da falta de incentivo por parte de órgãos que poderiam oferecer melhor qualificação para todos os produtores inseridos nesse processo produtivo.

A variável adubação, que compõe a formação do índice nos revela que no grupo 1 (índice muito baixo) que quatro (66,7\%) utilizam a adubação química, apenas 1 (17,7\%) utiliza a adubação orgânica e 1 irrigante $(17,7 \%)$ utiliza os dois tipos de adubação. O grupo 2 (índice baixo) nos revelou que quatro (36,4\%) utilizam adubação química, 1 (9,1\%) utiliza apenas o adubo orgânico e seis $(54,5 \%)$ irrigantes utilizam os dois tipos de adubação na cultura. O grupo 3 (índice médio) pode-se observar que oito irrigantes (47,1\%) utilizam apenas a adubação química, 1 $(5,9 \%)$ apenas a orgânica e sete $(41,2 \%)$ utilizam os dois tipos e apenas 1 irrigante $(5,9 \%)$ utiliza biocomposto. O grupo 4 (índice alto) dois $(33,3 \%)$ utilizam adubo químico, 1 (16,7\%) apenas o adubo orgânico e três (50\%) afirmarem fazer o uso dos dois tipos de adubação. Percebemos a presença de um percentual bastante significativo onde cerca de $45 \%$ dos irrigantes utilizam só a adubação química, o que no futuro pode gerar perda de produtividade e a modificação dos macronutrientes do solo.

Outra variável responsável pela construção do índice foi o investimento. 0 grupo 1 (índice muito baixo) percebemos que cinco (83,3\%) obtiveram empréstimos 
para sua produção e apenas $1(16,7 \%)$ respondeu que não obteve empréstimo. $O$ grupo 2 (índice baixo) sete irrigantes (63,6\%) afirmaram que realizaram empréstimos, quatro $(36,4 \%)$ afirmaram que não fizeram empréstimos. 0 grupo 3 (índice médio) observamos que sete $(41,2 \%)$ realizaram empréstimos para sua produção e dez irrigantes (58,8\%) não realizaram empréstimos. O grupo 4 (índice alto) dois produtores $(33,3 \%)$ obtiveram empréstimos para sua produção e quatro $(66,7 \%)$ não fizerem nenhum tipo de empréstimo. Observou-se que aqueles irrigantes que se encontram nos índices de muito baixo e baixo tem uma maior probabilidade de contrair empréstimos devido aos altos custos que a cultura exige inicialmente.

Tabela 06: Frequência absoluta e relativa das variáveis do fator 2 do índice dos irrigantes do município de Cariús, Ceará.

\begin{tabular}{|c|c|c|c|c|c|}
\hline \multirow[b]{2}{*}{ VARIÁVEIS } & \multicolumn{5}{|c|}{ ÍNDICES } \\
\hline & & $\begin{array}{c}\text { Grupo } 1 \\
\text { MUITO BAIXO }\end{array}$ & $\begin{array}{c}\text { Grupo } 2 \\
\text { BAIXO }\end{array}$ & $\begin{array}{l}\text { Grupo } 3 \\
\text { MÉDIO }\end{array}$ & $\begin{array}{c}\text { Grupo } 4 \\
\text { ALTO }\end{array}$ \\
\hline \multirow{15}{*}{ ESCOLARIDADE } & \multirow{2}{*}{ NA } & 1 & 2 & 2 & 0 \\
\hline & & $16,7 \%$ & $18,2 \%$ & $11,8 \%$ & $0,0 \%$ \\
\hline & \multirow{2}{*}{ EFI } & 5 & 8 & 10 & 0 \\
\hline & & $83,3 \%$ & $72,7 \%$ & $58,8 \%$ & $0,0 \%$ \\
\hline & \multirow[t]{2}{*}{ EFC } & 0 & $\begin{array}{c}1 \\
0\end{array}$ & 0 & 0 \\
\hline & & $0,0 \%$ & $9,1 \%$ & $0,0 \%$ & $0,0 \%$ \\
\hline & \multirow{2}{*}{ EMI } & 0 & 0 & 1 & 2 \\
\hline & & $0,0 \%$ & $0,0 \%$ & $5,9 \%$ & $33,3 \%$ \\
\hline & \multirow{2}{*}{ EMC } & 0 & 0 & 3 & 0 \\
\hline & & $0,0 \%$ & $0,0 \%$ & $17,6 \%$ & $0,0 \%$ \\
\hline & \multirow{2}{*}{ ES } & 0 & 0 & 0 & 3 \\
\hline & & $0,0 \%$ & $0,0 \%$ & $0,0 \%$ & $50,0 \%$ \\
\hline & \multirow{2}{*}{ TA } & 0 & 0 & 1 & 1 \\
\hline & & $0,0 \%$ & $0,0 \%$ & $5,9 \%$ & $16,7 \%$ \\
\hline & TOTAL & $\begin{array}{c}6 \\
100,0 \%\end{array}$ & $\begin{array}{c}11 \\
100,0 \%\end{array}$ & $\begin{array}{c}17 \\
100,0 \%\end{array}$ & $\begin{array}{c}6 \\
100,0 \%\end{array}$ \\
\hline \multirow{9}{*}{ ADUBAÇÃO } & \multirow{2}{*}{ QUÍMICA } & 4 & 4 & 8 & 2 \\
\hline & & $66,7 \%$ & $36,4 \%$ & $47,1 \%$ & $33,3 \%$ \\
\hline & \multirow{2}{*}{ ORGÂNICA } & 1 & 1 & 1 & 1 \\
\hline & & $16,7 \%$ & $9,1 \%$ & $5,9 \%$ & $16,7 \%$ \\
\hline & \multirow{2}{*}{$\begin{array}{l}\text { QUÍMICA E } \\
\text { ORGÂNICA }\end{array}$} & 1 & 6 & 7 & 3 \\
\hline & & $16,7 \%$ & $54,5 \%$ & $41,2 \%$ & $50,0 \%$ \\
\hline & BIOCOMPOSTO & $\begin{array}{c}0 \\
0 . \%\end{array}$ & 0 & $\begin{array}{c}1 \\
59 \%\end{array}$ & 0 \\
\hline & \multirow{2}{*}{ TOTAL } & 6 & 11 & 17 & 6 \\
\hline & & $100,0 \%$ & $100,0 \%$ & $100,0 \%$ & $100,0 \%$ \\
\hline \multirow{5}{*}{ INVESTIMENTO } & \multirow{2}{*}{ SIM } & 5 & 7 & 7 & 2 \\
\hline & & $83,3 \%$ & $63,6 \%$ & $41,2 \%$ & $33,3 \%$ \\
\hline & \multirow{2}{*}{ NÃO } & 1 & 4 & 10 & 4 \\
\hline & & $16,7 \%$ & $36,4 \%$ & $58,8 \%$ & $66,7 \%$ \\
\hline & TOTAL & $\begin{array}{c}6 \\
100 \%\end{array}$ & $\begin{array}{l}11 \\
100 \%\end{array}$ & 17 & 6 \\
\hline
\end{tabular}

Fonte: Elaborada com base nos resultados da pesquisa (2017)

Nota: AN - Analfabeto; EFI - Ensino Fundamental Incompleto; EFC - Ensino Fundamental Completo; EMI - Ensino Médio Incompleto; EMC - Ensino Médio Completo; ES - Ensino Superior; TA - Técnico Agrícola. 
A Tabela 07 mostra a análise, por grupo, de irrigantes em relação às variáveis representativas do fator 3 . Com relação a variável tempo de experiência observamos que no grupo 1 (índice muito baixo) 50\% dos irrigantes analisados tem de 2 a 5 anos de experiência e que os outros $50 \%$ responderam ter mais de 5 anos. $O$ grupo 2 (índice baixo) cerca de dois (18,2\%) responderam ter entre 2 a 5 anos de experiência e dez irrigantes $(58,8 \%)$ responderam ter mais de 5 anos. $O$ grupo 3 (índice médio) mostrou que sete $(41,2 \%)$ apresenta ter entre 2 a 5 anos de experiência e dez (58,8\%) afirmaram ter mais de 5 anos de experiência. $O$ grupo 4 (índice alto) nos revelou que apenas dois (33,3\%) tem entre 2 a 5 anos de experiência e quatro irrigantes $(66,7 \%)$ possuem mais de 5 anos de experiência. Pode-se concluir que cerca de $65 \%$ dos irrigantes possuem mais de 5 anos de experiência com a atividade, sendo esta primordial para o domínio e aumento de produtividade.

Tabela 07 - Frequência absoluta e relativa das variáveis do fator 3 do índice dos irrigantes do município de Cariús, Ceará.

\begin{tabular}{cccccc}
\hline \multirow{2}{*}{ VARIÁVEL } & \multicolumn{5}{c}{ ÍNDICES } \\
& & $\begin{array}{c}\text { Grupo 1 } \\
\text { MUITO BAIXO }\end{array}$ & $\begin{array}{c}\text { Grupo 2 } \\
\text { BAIXO }\end{array}$ & $\begin{array}{c}\text { Grupo 3 } \\
\text { MÉDIO }\end{array}$ & $\begin{array}{c}\text { Grupo 4 } \\
\text { ALTO }\end{array}$ \\
\cline { 2 - 6 } & \multirow{2}{*}{ DE 2 A 5 ANOS } & 3 & 2 & 7 & 2 \\
EXPERIÊNCIA & $50,0 \%$ & $18,2 \%$ & $41,2 \%$ & $33,3 \%$ \\
& & 3 & 9 & 10 & 4 \\
& MAIS DE 5 ANOS & $50,0 \%$ & $81,8 \%$ & $58,8 \%$ & $66,7 \%$ \\
& & $\mathbf{6}$ & $\mathbf{1 1}$ & $\mathbf{1 7}$ & $\mathbf{6}$ \\
& TOTAL & $\mathbf{1 0 0 , 0 \%}$ & $\mathbf{1 0 0 , 0 \%}$ & $\mathbf{1 0 0 , 0 \%}$ & $\mathbf{1 0 0 , 0 \%}$ \\
\hline
\end{tabular}

Fonte: Elaborada com base nos resultados da pesquisa (2017)

Após os resultados obtidos podemos concluir que com relação a assistência técnica cerca de $57,5 \%$ dos irrigantes afirmaram obter algum tipo de assistência técnica, quando volta-se o olhar para a utilização de mudas melhoradas percebe-se que cerca de $52,5 \%$ dos irrigantes fazem o uso de mudas selecionadas, dado que os maiores percentuais que utilizam se encontram nos grupos de muito baixo e baixo se mostrando como uma possível solução aumento de produtividade. Com relação cobertura morta $87,5 \%$ dos irrigantes afirmaram reconhecem a importância da preservação do solo e do aproveitamento da decomposição que a cobertura tem para a planta. No quesito fazer elaboração de projeto antes da cultura mostrou está em parcial $50 \%$ afirma que faz algum tipo de projeto e os outro não fazem, mas reconhecem a importância que o planejamento tem para o sucesso da atividade e como forma de controle de custos. Quando analisado a variável escolaridade percebe-se que cerca de $70 \%$ dos irrigantes possuem um baixo nível de 
escolaridade, sendo destes $12,5 \%$ responsável por analfabetos e 57,5\% por possuírem o ensino fundamental incompleto. $O$ que pode ser um grande entrave para adoção de novas tecnologias. Com relação a adubação cerca de $45 \%$ dos irrigantes afirmaram utilizar apenas a adubação orgânica, onde apenas 10\% respondeu utilizar apenas a orgânica. Fator importante a destacar e o valor significativo da utilização das duas formas de adubação responsáveis por 42,5\%. Quando observado a variável investimento cerca de 52,5\% dos irrigantes responderam ter feito algum tipo de empréstimo, importante destacar que o maior volume de irrigantes que responderam que fizeram o uso de empréstimos pertencem aos grupos do índice muito baixo e baixo o que pode ser resultado dos altos custos exigidos na produção inicial dentre outros. Observando a variável experiência podese concluir que cerca de $65 \%$ dos irrigantes possuem mais de 5 anos de experiência na atividade o que pode ser um ponto positivo para o domínio e o conhecimento do manejo.

\section{Determinação dos custos de produção mensais dos irrigantes do município de Cariús - Ceará}

Conforme a Tabela 08 percebe-se que os custos fixos e variáveis para os irrigantes somaram um valor de $\mathrm{R} \$ 534.656,50$ sendo que os custos fixos foram de $R \$ 225.307,50$ e os custos variáveis totalizaram $R \$ 309.349$. Observa-se que o os gastos com fertilizante foi o componente de maior impacto na composição dos custos variáveis das atividades produtivas, representando um percentual de 18,25\%, seguido dos gastos com mudas representando 12,31\% destes. Outros gastos, gastos com corretivos para o solo, composto orgânico, combustível e lubrificante e energia são os que impactam menos nos custos variáveis, representando um percentual de 0,79\%, 1,22\%, 2,12\%, 2,32\% e 4,44\%, respectivamente.

Para os custos fixos, destaca-se a remuneração do empresário como o fator de maior valor, totalizando $\mathrm{R} \$ 136.864$ respondendo por $25,60 \%$ dos custos fixos mensais dos irrigantes, seguidos da remuneração da terra $R \$ 30.450$ com um percentual de 5,70\% e mãe de obra com valor de $R \$ 29.760$ equivalendo a um percentual de $5,57 \%$ dos custos fixos. O que impactou em menor proporção foram os impostos e taxas com um percentual de $0,11 \%$ dos custos fixos.

Tabela 08 - Valor Total e percentual dos custos fixos e variáveis mensais dos irrigantes do município de Cariús, Ceará 2017. 


\begin{tabular}{ccc} 
Custos Variáveis & $\mathbf{3 0 9 . 3 4 9}$ & $\mathbf{5 7 . 8 6}$ \\
Mudas & 65.825 & 12.31 \\
Corretivos para o solo & 6.545 & 1.22 \\
Fertilizantes & 97.580 & 18.25 \\
Composto Orgânico & 11.340 & 2.12 \\
Defensivos & 41.279 & 7.72 \\
Mão de obra temporária & 46.400 & 8.68 \\
Energia & 23.750 & 4.44 \\
Combustíveis/Lubrificantes & 12390 & 2.32 \\
Outros & 4240 & 0.79 \\
Custos Fixos & $\mathbf{2 2 5 . 3 0 7 , 5}$ & $\mathbf{4 2 . 1 4}$ \\
Mão de Obra permanente & 29.760 & 5.57 \\
Gastos com Manutenção & 21.020 & 3.93 \\
Juros sobre Capital Médio & 6.608 .5 & 1.24 \\
Depreciação & - & - \\
Remuneração da terra & 30.450 & 5.70 \\
Remuneração do Empresário & 136.864 & 25.60 \\
Taxas e impostos & 605 & 0.11 \\
\hline CusTo ToTAL & $\mathbf{5 3 4 . 6 5 6 , 5}$ & 100.00 \\
\hline
\end{tabular}

Fonte: Elaboração a partir dos resultados da pesquisa (2017).

\section{Considerações Finais}

A partir dos dados analisados conclui-se que as características dos irrigantes são importantes para determinar o nível de tecnologia utilizado na produção, bem como a capacidade de pagamento pela água bruta. Desta forma, ao determinar os fatores que justificam o uso de adoção de tecnologia para estas atividades agrícolas, foram analisados cada fator por grupo de produtores, onde verifica-se que os grupos recebem ajuda de órgãos de assistência técnica com exceção dos produtores que foram classificados com altos níveis de tecnologia. Tal fato se confirma pela falta de apoio por parte dos órgãos que administram o município e a falta de técnicos para acompanha-los, contudo, seria muito importante a utilização dessa ferramenta para o aumento da produtividade da lavoura.

A utilização de mudas melhoradas é bem disseminada no município, contudo há aqueles que não a utilizam, principalmente em relação aos irrigantes que foram classificados com nível tecnológico baixo e muito alto. Ao iniciar sua atividade 
grande parte desses irrigantes não realizou nenhum tipo de projeto, entretanto, pôde-se perceber a importância que a realização de projetos tem para o produtor e para o sucesso de sua atividade agrícola.

Em relação à variável escolaridade, observou-se que prevalece um baixo nível entre os irrigantes, reflexo da falta de incentivo por parte de órgãos que poderiam oferecer melhor qualificação para todos os produtores inseridos nesse processo produtivo. Já o fator adubação, demonstra a presença de um percentual bastante significativo onde cerca de $45 \%$ no total dos irrigantes utilizam só a adubação química, o que no futuro pode gerar perda de produtividade e a modificação dos macronutrientes do solo. Com relação ao investimento pôde-se concluir que aqueles irrigantes que se encontram nos índices de muito baixo e baixo tem uma maior probabilidade de contrair empréstimos devido aos altos custos que a cultura exige inicialmente.

Analisando os custos mensais dos irrigantes, percebe-se que os custos fixos e variáveis somaram um valor de $R \$ 534.656,50$ sendo que os custos fixos foram de $R \$ 225.307,50$ e os custos variáveis totalizaram $R \$ 309.349$. Observa-se que o os gastos com fertilizante foi o componente de maior impacto na composição dos custos variáveis das atividades produtivas, representando um percentual de $18,25 \%$, seguido dos gastos com mudas representando $12,31 \%$ destes. Outros gastos, gastos com corretivos para o solo, composto orgânico, combustível e lubrificante e energia são os que impactam menos nos custos variáveis. Com relação aos custos fixos, destaca-se a remuneração do empresário como o fator de maior valor, totalizando $\mathrm{R} \$ 136.864$ respondendo por $25,60 \%$ dos custos fixos mensais dos irrigantes. O que impactou em menor proporção nestes custos foram os impostos e taxas.

As sugestões e contribuições da pesquisa são de que os órgãos que tratam do desenvolvimento de programas e políticas de desenvolvimento da agricultura do município desenvolvam ações junto a esses irrigantes para a formulação de cursos de capacitação e treinamento, de forma a permitir a adoção de práticas tecnológicas adaptadas, mais eficazes, que resultem em maiores produtividades e lucro para os produtores, bem como em maiores níveis de tecnologia. Visto de outra perspectiva, aconselha-se verificar a eficiência do uso da água na prática agrícola no município através de uma análise mais minuciosa, pois dada a escassez de recursos hídricos, o uso de forma inadequada pode gerar aumentos nos custos de produção. 


\section{REFERÊNCIAS}

Agência Nacional de Águas (Brasil). Conjuntura dos recursos hídricos: Informe 2016 / Agência Nacional de Águas - Brasília: ANA, 2016. 95 p. Disponível em: http://www.snirh.gov.br/portal/snirh/centrais-de-conteudos/conjuntura-dos-recursoshidricos/informe-conjuntura-2016.pdf. Acesso em: 25/06/2017.

ALFREDO, A. T. Irrigação: tecnologia e produtividade. Disponível em: <http://www.agr.feis.unesp.br/alfredo.htm > acesso em: 21/06/2017

BANCO DO NORDESTE. A importância do agronegócio da irrigação para o desenvolvimento do Nordeste. FRANÇA, Francisco Mavignier Cavalcante (coord.). Fortaleza: Banco do Nordeste, 2001.

CAMPOS, R. T. Capacidade de pagamento versus tarifa cobrada por água em um perímetro do estado do Ceará, Brasil. Anais... da Sociedade Brasileira de Economia, Administração e Sociologia Rural. 18 p. Fortaleza- CE, 2013.

CASTRO, C. N. A agricultura no Nordeste Brasileiro: oportunidades e limitações ao desenvolvimento. Instituto de Pesquisa e Estratégia Econômica Aplicada (IPEA). Textos para discursão. Rio de Janeiro. Novembro de 2012.

CAMPREGHER, R.; MARTINS, C. A Valoração econômica da água em contextos de ruralidade: síntese de estudo de caso; Il seminário internacional ruralidades, trabalho e meio ambiente. FAPESP, 2014.

CHRISTOFIDIS, D. Irrigação, a fronteira hídrica na produção de alimentos. Revista ITEM Irrigação \& Tecnologia Moderna, $n^{\circ}$ 54, 2ํㅡㄹ trimestre, 2002, p. 46-55.

CHRISTOFIDIS, D. Água, ética, segurança alimentar e sustentabilidade ambiental. Bahia análise \& dados. Salvador, v.13, n. ESPECIAL, p. 371-382, 2003. Disponível em < http://www.bvsde.paho.org/bvsacd/cd17/ageticsegu.pdf > Acesso em: 13/05/2015.

COGERH (Companhia de Gestão dos Recursos Hídricos). Disponível em < http://portal.cogerh.com.br/ > Acesso em: 01/08/2015.

FÁVERO, L. P. et al. Análise de dados: modelagem multivariada para tomada de decisões. Primeira edição. Rio de Janeiro. Elsevier. 2009, p.195-265.

FERRAZ. J. R. S.; Política nacional de recursos hídricos (LEI 9.433/97) e sua implementação no Distrito Federal. Rev. Fund. Esc. Super. Minist. Público Dist. Fed. Territ. Brasília, Ano, V. 17, p. 144 - 179, Jan. /Jun. 2001.

FERNANDEZ, J. C.; GARRIDO, R. S. O Instrumento de Cobrança pelo Uso da Água em Bacias Hidrográficas: Uma Análise dos Estudos no Brasil. Revista Econômica do Nordeste (REN), Fortaleza, v. 31, Documentos Técnico Científico, n. Especial, Novembro, 2000.

FREITAS, C. A.; BACHA, C. J. C. Contribuição do capital humano para o crescimento da agropecuária brasileira - período de 1970 a 1996. Revista Brasileira de Economia, Rio de Janeiro, vol. 58 no 04: p. 533-557, 2004.

GOMES, O. P. Perfil socioeconômico e tecnológico de produtores de fruticultura irrigada na região do Cariri, Ceará. Universidade Federal do Ceará, Centro de Ciências Agrárias-CCA (Dissertação de Mestrado). Departamento de Economia Agrícola, Programa de Pós-Graduação em Economia Rural, 2015, 77p. 
GUJARATI, D. N. Econometria Básica. 3 ed. São Paulo: Pearson Makron Books, 2000.

INESP (Instituto de Estudos e Pesquisas para o Desenvolvimento do Estado do Ceará). SANTANA, E.W (Org). INESP. Ceará. Assembleia Legislativa. Caderno Regional da Subbacia do Alto Jaguaribe / Conselho de Altos Estudos e Assuntos Estratégicos, Assembleia Legislativa do Estado do Ceará; Eudoro Walter de Santana (coordenador). - Fortaleza, 2009.

IPECE. (Instituto de Pesquisa e Estratégia Econômica do Ceará). Perfil básico municipal 2012 Cariús. Disponível em. <http://www.ipece.ce.gov.br/publicacoes/perfil_basico/pbm2012/Carius.pdf>. Acesso em 13/01/2015.

LANDIN, R. B. T. V. Uso do modelo dryrios na simulação de trocas hídricas entre o trecho do rio Jaguaribe e o aquífero aluvionar na bacia hidrográfica

Patos/Cariús/Iguatu - Ceará. Dissertação de mestrado - Universidade Federal do Ceará (UFC). Fortaleza, p.99, 2014. Disponível em: http://bdtd.ibict.br/vufind/Record/UFC7_ef8cd67e1932bafdbb3d9cf6f1647ac7/Details. Acesso em 17/10/2019.

LEMOS, J. J. S. Indicadores de Degradação no Nordeste Sub-umido e Semi-arido. In: Anais do Congresso Brasileiro de Economia e Sociologia Rural, 34, 2001, Brasilia, DF. Anais... Brasilia, DF: SOBER, 2001. p.1-10.

MADEIRA, S. A. Análise da modernização agrícola cearense no período de $1996 \mathrm{e}$ 2006. Fortaleza - CE. Universidade Federal do Ceará, Centro de Ciências Agrárias-CCA (Dissertação Mestrado). Departamento de Economia Agrícola, Programa de Pós-Graduação em Economia Rural, 2012, 93 p. Disponível em:

http://www.repositorio.ufc.br/bitstream/riufc/6273/1/2012_dis_samadeira.pdf. Acesso em $17 / 10 / 2019$.

MARTINS, R. C. A construção Social do Valor Econômico da Água: Estudo sociológico sobre agricultura, ruralidade e valoração ambiental no estado de São Paulo. Tese de doutorado. São Carlos: USP, 2004.

MARCONI, M. D. A.; LAKATOS, E. M. Técnicas de pesquisa: planejamento e execução de pesquisas, amostragens e técnicas de pesquisas, elaboração, análise e interpretação de dados. 3 ed. São Paulo: Atlas, 1996.

MATTAR, F. N. Pesquisa de marketing: edição compacta. São Paulo: Atlas, 1996.

MATTOS, J. C.; TOLEDO. J. C. Custos da qualidade: diagnóstico nas empresas com certificação ISO 9000. Revista Gestão \& Produção. Vol. 5, № 3. São Carlos, 1998.

MINGOTI, S. A. Análise de dados através de métodos de estatística multivariada: uma abordagem aplicada. Belo Horizonte: UFMG, 2005.p. 99-138.

NETO, R. S. M. Crescimento pró-pobre no nordeste do Brasil: uma análise dos períodos (1991-2000 e 2000-2010). Estudos Econômicos, v.44, n.3. São Paulo, Jul/Set 2014. Disponível em: <http://www.scielo.br/scielo.php?script=sci_arttext\&pid=S010141612014000300003>. Acesso em 17/10/2019.

OBERMAIER, M. Velhos e novos dilemas nos sertões: mudanças climáticas, vulnerabilidade e adaptação no semiárido brasileiro. Universidade Federal do Rio de Janeiro. 2011. Tese (Doutorado). Rio de Janeiro.

PINHEIRO, J. C. V.; LIMA, A. T. M. Valor econômico da água para irrigação: uma aplicação do método residual. In: III ENCUENTRO DE LAS AGUAS, 3., 2001, Santiago-Chile. Anais... 
Santiago, 2001. Disponível em: <http://.bvsde.paho.org/bvsacd/encuen/.pdf>. Acesso em: 16 jul. 2013.

PIMENTA, J. L.; BATISTA, L. D. Irrigação. UFRRJ, Instituto de Tecnologia, 2009.

SECRETARIA MUNICIPAL DE AGRICULTURA DE CARIÚS-CE. Rua 15 de novembro, no 19, Centro, Cariús-Ce. Antônio Ferreira de Melo (Secretário de Agricultura). Informação oral. Obtenção em 13/04/2015.

SILVA, J. P. Análise financeira de empresas. 4 ed. São Paulo: Atlas, 1999

SOUZA, J. J. B. Influência da tecnologia na capacidade de pagamento dos irrigantes do perímetro Platôs de Guadalupe no Estado do Piauí. Universidade Federal do Ceará, Centro de Ciências Agrárias-CCA (Dissertação Mestrado). Departamento de Economia Agrícola, Programa de Pós-Graduação em Economia Rural, Fortaleza, Ceará, 2014, 81p. Disponível em: http://www.repositorio.ufc.br/bitstream/riufc/15350/1/2014_dis_jjbsousa.pdf. Acesso em: 25/06/2017.

SOUZA, N. J. Desenvolvimento Econômico. 5. Ed. - 3 reimpr. - São Paulo: Atlas, 2008.

SANTOS, R. R. Irrigação como alternativa de sustentabilidade agrícola e ambiental. Revista multidisciplinar da UNIESP. Saber acadêmico - n 10 - dez. 2010.

\section{NOTAS DE AUTOR}

\section{CONTRIBUIÇÃO DE AUTORIA}

Yure Révelles da Silva Moura - Concepção. Coleta de dados. Análise de dados. Elaboração do manuscrito. Revisão e aprovação da versão final do trabalho

Otácio Pereira Gomes - Concepção. Elaboração do manuscrito. Participação ativa da discussão dos resultados. Revisão e aprovação da versão final do trabalho.

Fabiano Luiz Alves Barros - Elaboração do manuscrito. Participação ativa da discussão dos resultados; Revisão e aprovação da versão final do trabalho.

\section{FINANCIAMENTO}

Não se aplica.

CONSENTIMENTO DE USO DE IMAGEM

Não se aplica

\section{APROVAÇÃO DE COMITÊ DE ÉTICA EM PESQUISA}

Não se aplica.

CONFLITO DE INTERESSES

Não se aplica

\section{LICENÇA DE USO}

Este artigo está licenciado sob a Licença Creative Commons CC-BY. Com essa licença você pode compartilhar, adaptar, criar para qualquer fim, desde que atribua a autoria da obra.

\section{HISTÓRICO}

Recebido em: 08-10-2017

Aprovado em: 02-12- 2019 